\title{
Is There a "Logical Problem" of Second Language Acquisition?*
}

Lydia White

Arguments for universal grammar (UG) in generative theory are based on the socalled "logical problem of language acquisition." The nature of the problem becomes apparent when we consider the end product of the acquisition process and compare this to the input data, which do not seem sufficiently rich or precise to allow the learner to work out all the complexities of the adult grammar, unless one assumes the availability of certain innate principles (UG). In this paper, I will suggest that this orientation is also useful when one comes to consider second language acquisition. If we focus on the successful second language (L2) learner, it would appear that he or she will also achieve complex knowledge of the $\mathrm{L} 2$ which goes well beyond the input. This suggests that UG might have a role to play in L2 acquisition as well, and raises the question of whether the way that UG has operated in the L1 has any effects in L2 acquisition. I will briefly look at current $L 2$ research that presupposes a UG framework, as well as suggesting some directions for further research.

In this paper, I should like to consider the potential role for L2 acquisition of language universals as currently conceived of within generative grammar, and to try and outline what Universal Grammar (UG) attempts to explain and what it does not explain, before going on to consider what research this orientation suggests for the L2 field. In this framework, arguments for the existence of UG are motivated by a consideration of the so-called "logical problem" of first language acquistion (Hornstein and Lightfoot, 1981). I should like to suggest that second language learners are faced with a similar problem, and, hence, that it is worth investigating whether or not the same kind of solution to that problem (i.e. the assumed innateness of UG) is available to them. In other words, I shall be adopting an approach to universals which assumes that they have a basis in the human mind, in contrast to other approaches, which do not necessarily make this assumption. ${ }^{1}$

\section{UNIVERSAL GRAMMAR IN L1 ACQUISITION}

To make the point clear, it is necessary first to outline the generative approach to $\mathrm{L} 1$ acquisition. Unlike most work in developmental psycholinguistics, which tends to start with the young child's earliest stages of 
acquisition and to follow the developing grammar for a limited range of not particularly complex syntactic constructions, those approaching acquisition from the linguistic orientation do the opposite. That is, they look at properties of the adult grammar, the grammar that the child will eventually attain, and determine precisely how complex it is. This then raises the question of how the young child could ever acquire such complexity. It is this orientation that has led to the claim that there must be innate properties of grammar (or UG) available to the language learner, to explain certain aspects of the child's acquisition of linguistic competence.

The problem is that the input data available in the course of $\mathrm{Ll}$ acquisition fail to reveal enough about the subtleties and complexities of language for the child to arrive at knowledge of these on the basis of input alone. Native speakers, as well as knowing that various things are possible in their mother tongue, also know that various things are NOT possible, even though this is something they rarely think about, unless they happen to be language teachers. Nevertheless, this knowledge is a critical part of a person's linguistic competence and is something that any $\mathrm{L} 1$ learner will attain.

Let us consider some examples. Below, we have a number of sentences, some grammatical and others ungrammatical in English. The question is, how do language learners learn that the ungrammatical sentences are not possible, if the only evidence available to them is "positive evidence," in other words grammatical sentences?

1. a. The book is dull.

b. Is the book dull?

c. The book which is on the shelf is dull.

d. *Is the book which _ on the shelf is dull?

e. Is the book which is on the shelf _ dull?

In the case of the sentences in (1), we have examples of a simple statement and its corresponding question in (la) and (lb). On the basis of data of this kind, the learner might be justified in assuming that the rule for forming questions in English is something like "move the verb to the front." This possibility would lead the learner to produce questions like the ungrammatical (1d), where the first verb has been fronted. In fact, this is not something that children do; they seem to know, without being told, that linguistic rules must be what is called "structure-dependent," suggesting that they do not simply try out all the logical possibilities in their attempts to acquire language.

The next examples concern the question of how children learn that certain kinds of wh-question are perfectly possible, while others are not. In the sentences in (2a) and (2b), we see that the language learner would be 
justified in assuming some kind of rule that moves the wh direct object to the front of the sentence. He would be further justified if he assumed that this rule can be generalized beyond simple sentences: $(2 c)$ and $(2 d)$ are also perfectly grammatical. The problem is raised by $(2 e)$ and $(2 f)$. Why don't language learners extend their generalization to produce such sentences? Notice that the problem is only with the question forms; the statement versions of these sentences are perfectly grammatical and comprehensible. Nor is this simply a matter of sentence length; $(2 \mathrm{~g})$ is just as long and contains as many embeddings as the others but is acceptable.

2. a. Who did John see - ?

b. What did Mary buy - ?

c. Who did Fred believe (that) John saw _ ?

d. What did Jane think (that) Mary bought $\_$?

e.* Who did Fred believe the rumour that John saw _ ?

f.* What did Jane hear the news that Mary bought _ ?

g. Who do you think (that) Bill said (that) Susan saw - ?

The final examples concern the placement of lexical anaphoric pronouns like each other. Such pronouns have a restricted distribution. In simple sentences, reciprocals can occur in object position, as in (3a), but not subject position, as in (3b), whereas in embedded sentences they can occur in subject position, as in (3c), provided the sentence is not tensed, as in (3d). Furthermore, usually no NP must intervene between the reciprocal and its antecedent (compare (3e) and (3f)) but the antecedent isn't necessarily the NP immediately to the left of the reciprocal (3g). Other noun phrases, including pronouns, are not restricted in this way. Why don't children generalize the properties of noun phrases to this class of lexical anaphors? Children are notorious generalizers after all. How do they discover the limitations on the distribution of reciprocals?

3. a. The children are always fighting each other.

b. ${ }^{*}$ Each other are always fighting the children.

c. The men expected each other to win.

d. ${ }^{*}$ The men expected that each other would win.

e. The men expected to visit each other.

f.* The men expected Max to visit each other.

g. Who did the men expect to visit each other?

Let us dispose of a number of ways in which learners might come to this kind of knowledge. (Whilst I focus on arguments for $\mathrm{L} 1$ acquisition at this point, most of these will also be relevant for L2 acquisition).

a) Could it be that the ungrammatical sentences don't make sense and so can be rejected on semantic grounds? In fact, this is simply not true. Although some of them are hard to understand, e.g. (2e) and (2f), this 
cannot be for semantic reasons, since the equivalent statements are perfectly grammatical and comprehensible. The problem is a structural, syntactic one and will require a syntactic solution.

b) Could it be that they don't accept the ungrammatical sentences because they never hear them? This can hardly be the case; the acquisition literature, first and second, is full of examples of things that learners say in spite of not having heard them. Furthermore, people will accept sentences like $(2 \mathrm{~g})$ or (3e) in spite of not having heard them before, whilst not accepting sentences like (2f) or (3f).

c) Simplified input: a lot of recent work in L1 and L2 acquisition has concentrated on supposedly simplified characteristics of speech directed at language learners. Might such "simplified" input help to explain how learners acquire knowledge of the properties of complex sentences? It seems highly unlikely: by the time learners are working out the properties of sentential embeddings, etc., they will be past the stage of receiving this kind of input anyway. The simplified input proposals, if they can explain anything at all, can only be relevant to very early stages of acquisition. If mothers only utter simple sentences to children, it is not clear how they will work out properties of grammatically complex sentences, let alone work out which ones are ungrammatical. ${ }^{2}$

d) One might wish to argue that the fact that children learn simple sentences before complex sentences somehow solves this problem. This is not so; it is not clear that acquiring simple sentences before complex ones is going to help the learner to sort out problems which are specific to complex sentences alone. The properties of complex sentences are not simply the sum of the properties of simple sentences.

e) Negative evidence: if learners actually produced the ungrammatical sentences and then were corrected, this would also provide the means to acquire knowledge about which structures are not possible in the language being learned. However, $\mathrm{L} 1$ research suggests, firstly, that children do not make these kinds of errors anyway and, secondly, that they do not get reliable negative evidence as to the form of their utterances (e.g. Brown and Hanlon, 1970). A recent paper by Hirsh-Pasek et al., 1984 suggests that mothers do reveal sensitivity to ungrammatical forms produced by their children, but that this is only true for very young learners, again irrelevant for acquisition of complex syntax. A crude form of negative evidence might be available in the form of incomprehension (as proposed by Schacher, 1984 for L2 acquisition). Unfortunately, this isn't fine-tuned enough to give the learner any indication of where he has gone wrong, of whether he has been misunderstood because of problems of syntax, morphology, phonology or vocabulary choice, etc., so it is not clear how this could aid acquisition to any significant extent.

e) Properties of context, discourse, etc.: whilst there are, no doubt, many 
aspects of acquisition that can be helped by cues from situational context or by properties of the discourse situation, these would seem to be simply irrelevant to the issues being discussed here. For example, it is not clear how context or discourse factors could contribute at all to the learner's ultimate knowledge that (2c) is grammatical whereas (2e) is not.

When we focus on the complexities of syntax in the adult grammar, the acquisition problem becomes apparent. For reasons such as these, it is assumed that the child has "advance knowledge" of certain universal linguistic principles ${ }^{3}$ which constrain the form of grammars in various ways, guaranteeing that grammatical sentences can be learned on the basis of positive data without also giving rise to ungrammatical ones like those above. Where children do "go wrong," and produce ungrammatical constructions, they do so in structurally constrained ways. Most of the ungrammatical sentences given above are not attested as error types in $\mathrm{Ll}$ acquisition.

\section{L2 ACQUISITION}

Let us now turn to L2 acquisition. Notice that we can also look at L2 acquisition from the same perspective, although this has rarely been done in the past. That is, we can ask the question: what are the properties of the L2 grammar that the L2 learner hopes eventually to attain? Instead of concentrating on the developing L2 grammar and the fact that many L2 learners do not achieve total success in $\mathrm{L} 2$, let us rather concentrate on those learners who are relatively successful, and who success involves not just the ability to communicate but to communicate with some degree of syntactic accuracy. Such learners will presumably end up with unconscious knowledge as to what is and is not grammatical in the L2, and this will include knowledge about relatively complex structures, such as those discussed above. By focussing on successful learners and on the complexities of the target language we also get a clearer picture of what it is that unsuccessful learners fail to achieve. We may find that, as in $\mathrm{Ll}$ acquisition, their errors are of a much more limited range than might be expected.

For L2 acquisition one can ask the identical question to that posed for L1, namely whether the input data alone are sufficiently informative for the L2 learner to work out the complex properties of the target language and, again, it seems that they are NOT sufficiently rich. That is, the inadequacies of simplified input, negative data, context and discourse factors seem to be just as true for the L2 acquisition situation as they are for $\mathrm{L} 1 .^{4}$

This, then, raises the question: if we assume that the $\mathrm{L} 1$ learner has at his disposal certain universal principles which allow him to learn his 
language on the basis of positive input, principles which constrain grammars so that the learner never hypothesises ungrammatical sentences like those above, could it not also be the case that such principles are available to the L2 learner? In other words, is UG still active in L2 acquisition and, if so, is it active in adult learners as well as children?

Let us suppose, for the sake of the argument, that the answer is "yes," that $U$ G in some way mediates L2 acquisition, although this is something that clearly needs further research, since much of the existing research on language universals does not focus on this kind of issue at all. This does not necessarily mean that the situation is as straightforward as it is in L1. Given that the L2 learner already knows a language (the mother tongue), the question arises as to whether he is able, in L2 acquisition, in some sense to reactivate $U G$ for the $L 2$, unaffected by his $L 1$ experience, or whether the settings of UG established for the L1 have effects on L2 acquisition, i.e., can UG be reset to the null hypothesis for $\mathrm{L} 2$ or not?

This latter question has recently become of particular interest, because of developments in linguistic theory. Rather than being seen as invariant across languages, principles of UG are seen as subject to "parametric variation," in that there are certain limited options associated with a number of principles. The idea is that a particular principle is responsible for a number of properties within a language. If the language has that principle "set" in a particular way, a certain range of consequences results. Another language might have the principle "set" differently, with different consequences. A limited number of parameters, or options, will, theoretically, account for considerable diversity in the world's languages. As an example, consider the so-called "pro-drop" parameter (e.g. Chomsky, 1981; Rizzi, 1982), as in (4):

4. The pro-drop parameter:

a. Empty subjects - Anda muy ocupada

*Is very busy

She is very busy

b. Inversion - Vino Juan

* Came Juan

Juan came

c. Subject extractions - Quien dijiste que - vino?

* Who did you say that _ came?

Who did you say _ came?

The idea is that $+/$ - pro-drop is a parameter of UG; + is triggered by languages with null subjects, such as Spanish and Italian, whereas - is triggered in languages which require explicit subjects, such as English or French. When + is triggered, the effects listed in $4 a, b$, and $c$ are found. It can be seen that, if correct, this concept is of considerable potential 
interest to L2 acquisition research, since it makes it possible to consider the question of the influence of the L1 within the framework of UG, unlike many accounts of language transfer which have had to assume that transfer is somehow distinct from universal factors. Some L2 learners will be in situations where $\mathrm{L} 1$ and $\mathrm{L} 2$ coincide with respect to a parameter, whereas others will be faced with learning a language where the L1 parameter for some principle differs from the $\mathrm{L} 2$. The latter circumstance allows one to test for the question of whether UG in L2 acquisition can revert to the null hypothesis, in which case one would expect no transfer effects, or whether the L1 parameter setting in some way intrudes in L2 acquisition, in which case transfer will be predicted, at least initally. If the latter is the case, there are certain implications for language teaching, I believe, implications that show, for example, that positive evidence alone will not always suffice, that "comprehensible input" (see Krashen, 1982 and elsewhere) will be inadequate to allow for the acquisition of certain structures in certain circumstances, a point to which I shall return.

\section{CURRENT RESEARCH AND FUTURE RESEARCH ISSUES}

I should like now to outline some research questions that are raised by this view of $\mathrm{L} 2$ acquisition, and to discuss briefly to what extent existing research is supportive.

1. The first research issue is the most basic one. That is, is there evidence that second language learners observe the same kinds of constraints as are assumed for $\mathrm{L} 1$ acquisition? This can only be looked at indirectly, and one can start by seeing whether L2 learners do, at any age or stage, attain the kind of complex knowledge that motivates arguments for UG and whether, when they make mistakes, these are ones that would be considered violations of UG. In recent L2 acquisition research, of course, there have been many studies of the role of linguistic universals, though these are not always closely identified with the UG of generative grammar. For example, Dulay, Burt and Krashen (1982) assume universal factors at work within what they call the "organizer" in their model of L2 acquisition, i.e., universals do seem to have "pasychological reality" for them, to be part of one's mental capacity. However, they nowhere specify the content of the organizer, so that one doesn't really know what precise claims are being made, nor how to test them. ${ }^{5}$ Many have also investigated universal acquisition processes but this is an independent issue: the assumption of universal acquisition processes does not entail the acceptance of universal grammar.

To pursue the question of whether UG is involved in L2 acquisition, 
one must have some theory as the what is universal, as to precisely what it is that the learner brings to the acquisition task. Such a theory is provided by generative gammar, so that the claims for a universal component are at least testable; one can take principles of $U G$ and the kinds of sentences they do and do not allow and see whether L2 learners in some sense "know" this without being taught. Researchers who have looked at whether specific universal principles are obeyed in L2 acquisition include Schmidt (1980), who looked at whether L2 learners violate general constraints on the formation of coordinate structures. She found that whilst errors do occur, they do not violate universals. Ritchie (1978) found that Japanese learners of ESL appear to observe constraints dictating when rightward movement is possible in English and when it is not.

2. An issue related to (1) is whether UG is available to adult learners as well as to children. Several recent papers have focussed on the adult learner, and have suggested that UG does still mediate adult L2 acquisition (Adjémian and Liceras, 1984; Flynn, 1984; White, 1984b, 1985). However, more specific comparison of child to adult acquisition for specific principles would be appropriate, given that proponents of the critical period hypothesis often assume that UG is not available to adult learners, although these arguments tend to be based on the acquisition of phonology rather than syntax.

3. Another question of interest is whether the Ll parameter-setting affects L2 acquisition in any way and, if it does, whether this is the case for all parameters or whether the markedness of a parameter also has effects. ${ }^{6}$ For example, to take the case of pro-drop, does it cause problems if you are learning a pro-drop language as a native speaker of a non pro-drop language, or vice versa? Is it equally problematical both ways? In a number of recent papers studying the acquisition of ESL by native speakers of Spanish (White, 1984b, 1985), I have found that such learners seem to assume that English is also a pro-drop language, i.e., the L1 parameter is carried over. Flynn (1984) shows that the branching direction (or word order) of the $\mathrm{L} 1$ has effects on the acquisition of anaphora in the L2. Such results suggest that UG cannot be reset to the null hypothesis for the L2, or not without considerable difficulty. However, others argue that the L1 has minimal effects as far as UG is concerned (e.g. Mazurkewich, 1984).

4. Since many parameters are thought to have a range of effects, or to lead to a clustering of properties previously thought to be unconnected, another line of investigation is to see whether they also have a range of effects in the L2 learner's interlanguage. In acquiring some structure relevant to a parameter, do the other aspects of that parameter "fall out," so to speak? If a parameter is transferred from the $\mathrm{Ll}$, are all aspects transferred? In the work mentioned above, I found that some but not all aspects of the pro-drop parameter were transferred to English. ${ }^{7}$ Flynn's 
work also suggests that having to learn an L2 with different parameters can have a range of effects. This kind of question needs to be further investigated, since it constitutes a particularly interesting aspect of current linguistic claims as far as L2 acquisition is concerned.

All the points raised so far bring up a general methodological question, namely what is the best way to establish whether or not L2 learners do these things? Given that, in many cases, we are interested in what learners know about ungrammaticality, and given the complexity of some of the structures involved, it seems clear that we cannot simply wait for errors to show up in production data. Indeed, if L2 learners do still have access to UG, we would not expect the relevant errors to show up at all. Hence, grammaticality judgment tasks will be a very important source of data, a means to tap learner intuitions about the $\mathrm{L} 2$, and refinements in grammaticality judgments task methodologies will be extremely useful.

5. Teaching implications. Parametric differences between L1 and L2 may lead to certain problems that need special treatment in the classroom. In certain cases, positive input alone may not suffice for L2 acquisition. Take the case of the principle of adjacency of case assignment (Stowell, 1981). In English, nothing can intervene between a verb and its direct object, as can be seen below:

5. a. Mary ate her dinner quickly.

b. Quickly, Mary ate her dinner.

c. Mary quickly ate her dinner.

d. Mary has quickly eaten her dinner.

e.* Mary ate quickly her dinner.

Since adverbs are normally very free in their positions in English, it is not clear how the $\mathrm{L} 1$ learner knows that $(5 \mathrm{e})$ is not possible unless he has advance knowledge of some principle like adjacency which says that NPs must be next to the verb or preposition which gives them (abstract) case. In (5e), the adverb intervenes between the direct object and its case assigner, whereas this is not so for any of the other sentences in (5). In English, adjacency is quite strict; however, there are languages, such as French, which allow certain non-argument adverbs to intervene between the verb and the direct object. In French, sentences like (5e) would be grammatical, as in (6):

6. Marie a mangé rapidement le dîner

This suggests that adjacency is subject to parametric variation: some languages exemplify the "strict" option, whereas others do not. Suppose that L1 learners assume strict adjacency as the unmarked case. If they are learning English, this will be correct. If they are learning French, they will receive evidence, in the form of sentences like (6), that this must be 
modified. Now, what happens in the L2 situation? Do all learners assume strict adjacency for the L2, regardless of the situation in the L1? If so, one would not expect native speakers of French to make errors like (5e). On the other hand, if the $\mathbf{L} 1$ has an influence, then errors like (5e) might be expected. This is currently being investigated experimentally, but just relying on my intuitions as a teacher, it seems that errors like (5e) are quite common in the L2 situation. Now consider the problem that such errors raise: the positive input data from the $\mathrm{L} 2$ show that the sequence [verb object] is possible. They do not explicitly show that the sequence [verb adverb object] is impossible. In other words, there is nothing in the positive input, which will tell the learner that he has gone wrong if he makes a mistake like (5e). Contrast this with the native speaker of English learning French. Suppose that he initially fails to produce sentences like (6), either because of the L1 influence or because strict adjacency is the unmarked case. He will nevertheless encounter sentences like (6) in the input, which will suggest that such sentences are possible, so that he does not have to be taught specifically that such an order is available in French. Thus, the native speaker of English learning French will not face any particular difficulty with respect to this aspect of adverb order, whereas the native speaker of French learning English may well run into difficulties, which cannot be got out of on the basis of positive input alone. I suggest that such situations, where there are different directional effects should be investigated experimentally and pedagogically, to see whether, in such circumstances, rather specific "fine-tuned" teaching is in fact beneficial. ${ }^{8}$ In other words, there may be some circumstances where corrective teaching, or negative data, are useful in the classroom. ${ }^{9}$

\section{CONCLUSION}

In conclusion, I would like to suggest that the generative approach to language universals not only offers an orientation which forces one to think about L2 acquisition in terms of the desired end product and the problem of how this can be acquired, parallel to the L1 logical problem, but also offers a precise characterization of what those universals are, so that testable claims can be made. It is, of course, possible that whilst there is a "logical problem" for L2 acquisition, the solution to it is to be achieved in a different fashion from that available to the $\mathrm{L} 1$ learner. But in order to investigate such possibilities too, one needs to have some idea of the complexity of the target grammar, in order to come up with alternative proposals as to how it might be learned. I do not, however, wish to claim that a concept like UG offers a potential explanation of all aspects of L2 acquisition; clearly it cannot, since there are many aspects of 
language that have to be acquired that fall outside its domain, such as the acquisition of pragmatic competence and properties of discourse.

\section{FOOTNOTES}

* An earlier version of this paper was presented at the Second Language Research Forum, Los Angeles, Feb. 1985.

1. This does not mean that the various approaches to language universals are incompatible. For example, the fact that there are many statistical universal tendencies in the world's languages (c.f. Greenberg, 1968; Comrie, 1981) may be a reflection of properties of the human mind, as may universals of diachronic change. For the relationship to L2 acquisition of approaches to universals which do not necessarily assume their psychological basis, see papers in Rutherford (1984).

2. See Wexler and Culicover (1980) for discussion.

3. I leave aside the question of whether these innate principles might ultimately prove to be cognitive but not specifically linguistic. This seems, at present, to be an unanswerable question. By looking at the complexities of language, we get an idea of what these principles must account for, whether they turn out to be linguistically based or not.

4. In fact, many $\mathrm{L} 2$ learners may differ from $\mathrm{L} 1$ learners in that negative evidence is available, in the form of correction in the classroom, and there seem to be specific circumstances where this could be advantageous, a point to which I shall return. However, the existence of negative data is not sufficient to explain all aspects of complex L2 syntax acquisition, especially if L2 learners do not make the relevant mistakes.

5. The finding of universal morpheme acquisition orders, for example, does not help us to determine aspects of the acquisition of syntax, nor do they seem of fall out from any theory as to what the universals might be. See Gregg (1984) for similar observations.

6. I have suggested elsewhere (White, 1984a) that switching some parameters is far more problematic than others. For example, if $\mathrm{L} 1$ and $\mathrm{L} 2$ differ as to head position, the positive data in the two languages are in contrast, and hence it should not be problematic to learn that $\mathrm{L} 2$ order differs from L1. However, where L2 data are partially consistent with L1 data, it may be harder to see that the positive data in L2 motivate a different parameter setting; this may be the case with pro-drop.

7. However, Zobl (personal communication) suggests that my grammaticality judgment task may have been unsuitable for tapping one aspect of the parameter, namely VS (verb-subject) word order, which is particularly susceptible to discourse factors, so that its failure to show up may have been unrepresentative of the learners' interlanguage. Rutherford (personal communication) reports VS order in production data from native speakers of Spanish learning English, suggesting that this aspect of the parameter, like the others, is indeed subject to transfer.

8. See Rutherford and Sharwood Smith (1985) for suggestions as to how situations like this may be approached pedagogically.

9. It is, of course, possible that in circumstances like those outlined here, there are, in fact, other, more indirect sources of relevant positive evidence, which could lead the learner to drop forms like (5e) without the benefit of correction. That is, other properties of language might relate to the adjacency question, and hence provide the necessary positive data. However, even if this is the case, negative data might provide a short cut for the learner before he becomes aware of this more indirect positive data. Again, this is a matter amenable to experimental investigation. 


\section{REFERENCES}

Adjémian, C. and J. Liceras. (1984). Accounting for adult acquisition of relative clauses: universal grammar, $\mathrm{Ll}$ and structuring the intake. In F. Eckman, L. Bell and D. Nelson (eds). Universals of Second Language Acquisition. Rowley, Mass: Newbury House.

Brown, R. and C. Hanlon. (1970). Derivational complexity and the order of acquisition in child speech. In J. Hayes (ed), Cognition and the Development of Language. New York: Wiley.

Chomsky, N. (1981). Lectures on Government and Binding. Dordrecht: Foris. Comrie, B. (1981). Language Universals and Language Typology. Chicago: University of Chicago Press.

Dulay, H., M. Burt and S. Krashen. (1982). Language Two. Oxford: Oxford University Press.

Flynn, S. (1984). A universal in L2 acquisition based on a PBD typology. In F. Eckman, L. Bell and D. Nelson (eds). Universals of Second Language Acquisition. Rowley, Mass: Newbury House.

Greenberg, J. (1966). Some universals of grammar with particular reference to the order of meaningful elements. In J. Greenberg (ed), Universals of Language. Cambridge, Mass: M.I.T. Press.

Gregg, K. (1984). Krashen's monitor and Occam's razor. Applied Linguistics. 5: 79-100.

Hirsh-Pasek, K., R. Treiman and M. Schneiderman. (1984). Brown and Hanlon revisited: mothers' sensitivity to ungrammatical forms. J. Child Language. 11: 81-88.

Hornstein, N. and D. Lightfoot (eds). (1981). Explanation in Linguistics: the Logical Problem of Language Acquisition. London: Longman.

Krashen, S. (1982). Principles and Practice in Second Language Acquisition. Oxford: Pergamon.

Mazurkewich, I. (1984). The acquisition of the dative alternation by second language learners and linguistic theory. Language Learning. 34: 91-109.

Ritchie, W. (1978). The right-roof constraint in an adult-acquired language. In W. Ritchie (ed), Second Language Acquisition Research: Issues and Implications. New York: Academic Press.

Rizzi, L. (1982). Issues in Italian Syntax. Dordrecht: Foris.

Rutherford, W. (ed.). (1984). Language Universals and Second Language Acquisition. Amsterdam: John Benjamins.

Rutherford, W. and M. Sharwood Smith. (1985). Core grammar in pedagogy: principles of consciousness-raising in pedagogical grammar. Applied Linguistics, in press.

Schachter, J. (1984). A universal input condition. In W. Rutherford (ed). Language Universals and Second Language Acquisition. Amsterdam: John Benjamins.

Schmidt, M. (1980). Coordinate structures and language universals in interlanguage. Language Learning. 26: 67-76.

Stowell, T. (1981). Origins of Phrase Structure. PhD dissertation; M.I.T.

Wexler, K. and P. Culicover. (1980). Formal Principles of Language Acquisition. 
Cambridge, Mass: M.I.T. Press.

White, L. (1984a). Universal grammar as a source of explanation in second language acquisition. Paper presented at the 13th annual University of Wisconsin-Milwaukee Symposium on Current Approaches to Second Language Acquisition, March 1984.

White, L. (1984b). Implications of parametric variation for adult second language acquisition: an investigation of the PRO-drop parameter. To appear in V. Cook (ed), Experimental Approaches to Second Language Learning. Oxford: Pergamon Press.

White, L. (1985). The PRO-drop parameter in adult second language acquisition. Language Learning. 35.

\section{THE AUTHOR}

Lydia White has a TESL Certificate from Concordia University and a Ph.D. in Linguistics from McGill. She is currently teaching courses in first and second language acquisition in the McGill Linguistics Department. She has also taught ESL and has taught in the TESL program at Concordia. Her research interests include the relevance of current linguistic theories to theories of first and second language development. 
